\title{
Ion Transport across a Bilayer Lipid Membrane in the Presence of a Hydrophobic Ion
}

\author{
Keisuke Sasakura, Shintaro Kubota, Jun Onishi, Shunsuke Ozaki, Kenji Kano, \\ and Osamu SHIRAI*
}

Division of Applied Life Sciences, Graduate School of Agriculture, Kyoto University (Sakyo, Kyoto 606-8502, Japan)

Received March 25, 2008 ; Accepted June 20, 2008

\begin{abstract}
The ion transport from one aqueous (W1) to another (W2) across a bilayer lipid membrane (BLM) in the presence of a hydrophobic ion, dipicrylaminate $\left(\mathrm{DPA}^{-}\right)$, was investigated by cyclic voltammetry when the hydrophilic salt such as $\mathrm{LiCl}, \mathrm{NaCl}, \mathrm{KCl}$ or $\mathrm{CsCl}$ was used as a supporting electrolyte. Voltammograms for the ion transport at a lower scan rate than $10 \mathrm{mV} \mathrm{s}^{-1}$ were in steady state and showed sigmoid curves. The magnitude of the ion transport current density at a given potential was proportional to the hydrophobicity of the counter cation. The result supports our proposed mechanism that the hydrophobic ion serves as a carrier compound in the BLM for the ion transfer of the hydrophilic counter ion in the presence of the membrane potential gradient.
\end{abstract}

Key Words : Bilayer Lipid Membrane, Hydrophobic Ion, Ion Transport, Voltammetry

\section{Introduction}

Ion transport across a bilayer lipid membrane (BLM) has been investigated for the fundamental understanding of the feature of ion transport across biomembranes. It is known that ion transport occurs easily across a BLM in the presence of hydrophobic ions, though the BLM serves as an energy barrier for the transfer of hydrophilic ions. ${ }^{1,2}$ It is frequently stated that the ion transport current is simply ascribed to the transfer of the hydrophobic ion $\left(\mathrm{X}^{-}\right)$itself across the $\mathrm{BLM}{ }^{3-5)}$ as shown in Fig. 1 (a). Based on the conventional mechanism of the ion transport, however, it is difficult to explain the characteristics of voltammograms such as current density, wave form, effects of the counter ion. In addition, the electroneutrality in the BLM and aqueous phase (W) has hardly been taken into account.

We have proposed a new model of ion transport across the BLM, as shown in Fig. 1 (b). In the proposed mechanism, the hydrophilic ion $\left(\mathrm{M}^{+}\right)$distributes from $\mathrm{W}$ into the BLM spontaneously as the counter ion of the hydrophobic ion $\left(\mathrm{X}^{-}\right)$and not only the hydrophobic ion but the hydrophilic counter ion transfers between W1 and $\mathrm{W} 2{ }^{6,7)}$ In this case, the hydrophobic ion serves as a carrier compound of the hydrophilic counter ion in the presence of the membrane potential gradient. This model indicates that the hydrophilic counter ion is a key factor determing the ion transport current density. The proposed model was proved for the cases where the BLM contains ion carrier compounds, channel forming polypeptides, or uncouplers. ${ }^{8-10)}$

In the present work, cyclic voltammetric characteristics were examined for the ion transport across a BLM in the presence of dipicrylaminate ( $\left.\mathrm{DPA}^{-}\right)$as a typical hydrophobic ion and the relation was evaluated between the ion transport current density and the distribution ratio of both $\mathrm{DPA}^{-}$and the counter hydrophilic ion.

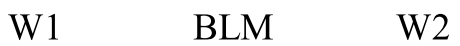

(a)

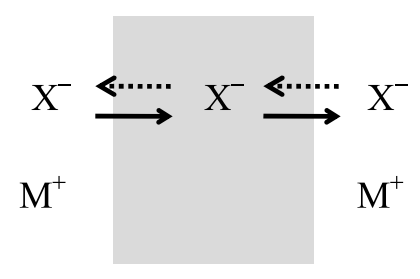

(b)
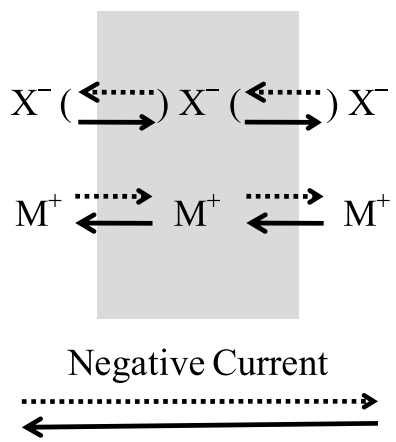

Positive Current

Fig. 1 The schematic model of ion transport mechanisms in the presence of a hydrophobic anion. $\mathrm{M}^{+}$: hydrophilic caion, $\mathrm{X}^{-}$: hydrophobic anion. (a) conventional model and (b) our proposed model.

\section{Experimental}

\section{1 Chemicals}

The lipids used to form a BLM were lecithin (Wako Pure Chemical Ind., Ltd., No. 124-05031) and cholesterol (Kanto Chemical Co., Inc., No. 07331-30). All other reagents were of reagent grade and used without further purification.

\section{2 Preparation of BLMs}

The electrochemical cell used for the experiments was the same as that used in previous works. ${ }^{6,7)}$ The cell has 


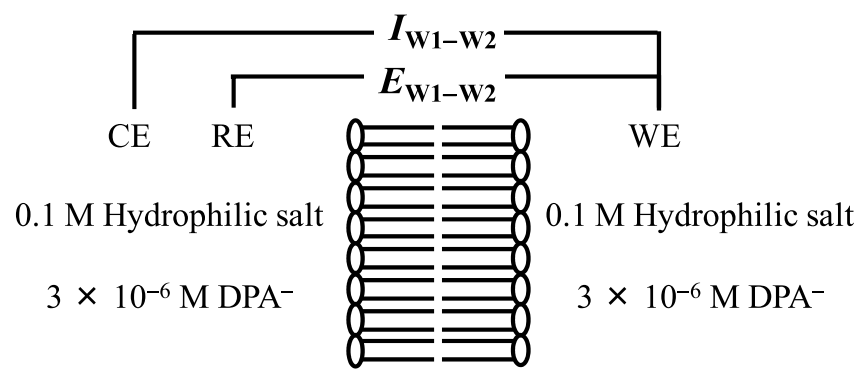

W1

BLM

W2

Fig. 2 The BLM system employed in the present work. Hydrophilic salt ( $\mathrm{LiCl}, \mathrm{NaCl}, \mathrm{KCl}$ or $\mathrm{CsCl}$ ) was used as a supporting electrolyte in the aqueous phase.

two aqueous compartments separated by a tetrafluoroethylene resin sheet with a thickness of $0.2 \mathrm{~mm}$, and the compartments were filled with $15 \mathrm{~mL}$ of aqueous solution. The BLM-forming solution was prepared by dissolving $10 \mathrm{mg}$ of lecithin and $5 \mathrm{mg}$ of cholesterol in $1 \mathrm{~mL}$ of $n$-decane. The BLM was obtained as a black lipid membrane by brushing the $n$-decane solution of lipids on a $1 \mathrm{~mm}$ diameter aperture created on the tetrafluoroethylene resin sheet. ${ }^{11)}$ The formation of BLM was confirmed by a microscopic observation and capacitance measurements.

\section{3. Voltammetric measurements}

The BLM system employed in this work is shown in Fig. 2. The electrochemical cell was placed in a Faraday cage in order to decrease back ground noise during the electrochemical measurements. Voltammetric measurements for the ion transport between $\mathrm{W} 1$ and $\mathrm{W} 2$ across a BLM were performed on a three-electrode potentiostat (Hokuto Denko Co., HSV-100) at $25 \pm 1{ }^{\circ} \mathrm{C}$. The potential difference, $E_{\mathrm{W} 1-\mathrm{W} 2}$, was applied between two $\mathrm{Ag} \mid \mathrm{AgCl}$ electrodes (WE and $\mathrm{RE}$ ) and the current $\left(I_{\mathrm{W} 1-\mathrm{W} 2}\right)$ between $\mathrm{WE}$ and $\mathrm{Pt}$ wire electrode $(\mathrm{CE})$ was recorded. Cyclic voltammograms were done at a rate of $1 \mathrm{mV} \mathrm{s} \mathrm{s}^{-1}$ unless otherwise noted. The current density $\left(j_{\mathrm{W} 1-\mathrm{W}_{2}}\right)$ was obtained by dividing $I_{\mathrm{W} 1-\mathrm{W} 2}$ by the area of the BLM.

\section{Results and Discussion}

Figure 3 shows cyclic voltammograms for the ion transport between $\mathrm{W} 1$ and $\mathrm{W} 2$ containing $0.1 \mathrm{M} \mathrm{CsCl}$ as a supporting electrolyte by scanning $E_{\mathrm{W} 1-\mathrm{W} 2}$ at $1 \mathrm{mV} \mathrm{s}^{-1}$ in the potential region between -120 and $+120 \mathrm{mV}$. In the absence of $\mathrm{DPA}^{-}$, no Faradaic current was observed. In the presence of $3 \times 10^{-6} \mathrm{M} \mathrm{DPA}^{-}$in $\mathrm{W} 1$ and $\mathrm{W} 2$, however, voltammograms were in steady state and showed

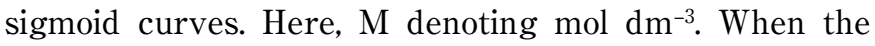
other hydrophilic salt $(\mathrm{LiCl}, \mathrm{NaCl}$ or $\mathrm{KCl}$ ) was used as the supporting electrolyte, the voltammetry gave a wave with forms and characteristics similar to those in the case of $0.1 \mathrm{M} \mathrm{CsCl}$. The current densities, however, depended on the hydrophilic supporting electrolytes at the given $E_{\mathrm{W} 1-\mathrm{W} 2}$.

It is well known that the ion transport current density has been described by Goldman-Hodgkin-Katz equation, when the mass transfer within the BLM is the ratedetermining step. ${ }^{2)}$ The current density is proportional to

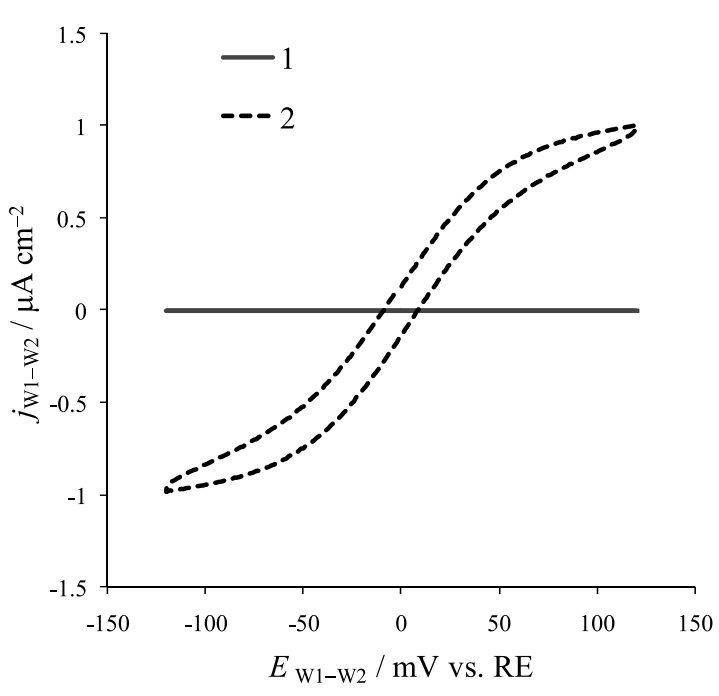

Fig. 3 Cyclic voltammograms for the ion transport across a BLM. Curve 1, 0.1 M CsCl in both $\mathrm{W} 1$ and W2; curve 2, as curve 1 , but in the presence of $3 \times 10^{-6} \mathrm{M} \mathrm{DPA}^{-}$in $\mathrm{W} 1$ and W2. Scan rate of $E_{\mathrm{W} 1-\mathrm{W} 2}: 1 \mathrm{mV} \mathrm{s}^{-1}$.

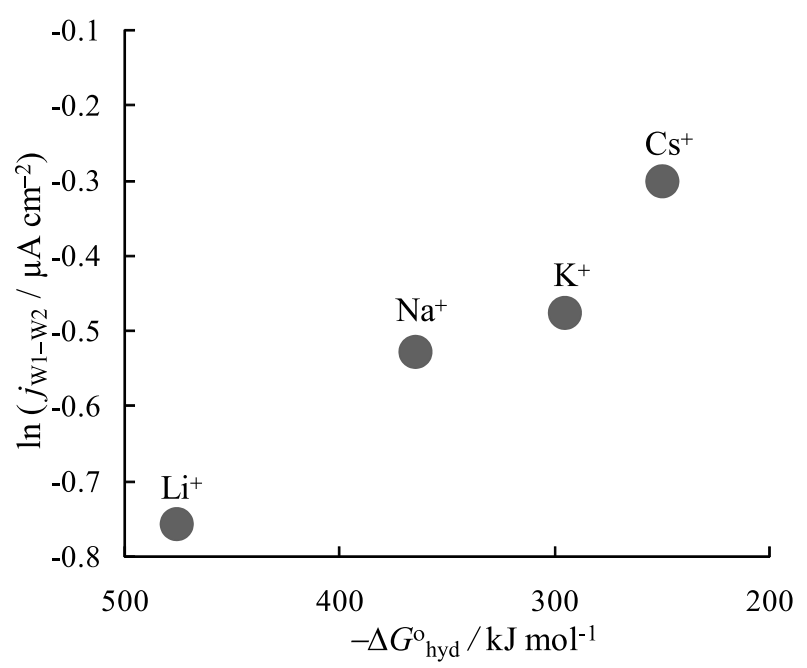

Fig. 4 The dependence of $\ln \left(j_{\mathrm{W} 1-\mathrm{W} 2}\right)$ at $50 \mathrm{mV}$ on the molar Gibbs energy of the hydration, $\Delta G_{\text {hyd. }}^{\circ}{ }^{14)}$ Electrolyte in W1 and W2: $0.1 \mathrm{M} \mathrm{MCl}\left(\mathrm{M}=\mathrm{Li}^{+}, \mathrm{Na}^{+}, \mathrm{K}^{+}, \mathrm{Cs}^{+}\right)$.

permeation coefficient $(P)$, which is a function of distribution coefficient of the ion between $\mathrm{W}$ and the $\operatorname{BLM}(\beta)$, diffusion coefficient of the ion $(D)$, and the thickness of the BLM $(d)$, and is given by;

$$
P=\beta D / d
$$

When the BLM is regarded as an organic phase, $\beta$ of $\mathrm{M}^{+}$and $\mathrm{X}^{-}\left(\beta_{\mathrm{M}^{+}}\right.$and $\left.\beta_{\mathrm{X}^{-}}\right)$can be related to the standard Gibbs transfer free energies of $\mathrm{M}^{+}$and $\mathrm{X}^{-}$from $\mathrm{W}$ to $\operatorname{BLM}\left(\Delta G^{\mathrm{o}}{ }_{\mathrm{r}, \mathrm{M}^{+}}\right.$and $\left.\left.\left.\Delta G^{\mathrm{o}}{ }_{\mathrm{tr}, \mathrm{X}}^{-}\right)\right)^{12}\right)$

$$
\ln \beta_{\mathrm{M}^{+}} \beta_{\mathrm{X}^{-}}=-\left(\Delta G^{\mathrm{o}}{ }_{\mathrm{tr}, \mathrm{M}^{+}}+\Delta G_{\mathrm{tr}, \mathrm{X}^{-}}^{\mathrm{o}}\right) / R T
$$

Combination of Eqns (1) and (2) suggests that $j_{\mathrm{W} 1-\mathrm{W} 2}$ depends on the hydrophobicity of not only the hydrophobic ion but the counter ion. The $\Delta G^{\circ}$ tr value, however, is not 
evaluated exactly, because the BLM is too thin to measure the ion concentration. Therefore, we may utilize the hydration energy $\left(\Delta G^{\circ}\right.$ hyd $)$, which is energy required for dehydration, of the ion as a measure of $\Delta G^{\circ}$ tr by considering the fact that $\Delta G_{\text {hyd }}^{\circ}$ is proportional to $\Delta G_{\text {tr }}^{\circ}$ from W to organic solvents such as nitrobenzene, 1,2dichroloethane. . $^{13,14)}$

Figure 4 shows the relation between the hydration energy of the alkali metal ions and natural logarithm of $j_{\mathrm{W} 1-\mathrm{W} 2}$ at $50 \mathrm{mV}$ in the steady-state voltammograms. Similar characteristics were observed at any other $E_{\mathrm{W} 1-\mathrm{W} 2}$. Clear linear relation between $\ln \left(j_{\mathrm{w} 1-\mathrm{w} 2}\right)$ and $\Delta G_{\text {hyd }}^{\circ}$ of the alkali metal ions indicates that the hyrophobicity of the alkali metal ion as a counter ion is significant factor determining $j_{\mathrm{W} 1-\mathrm{W} 2}$ and verifies our proposed model (Fig. 1 (b)).

In conclusion, the proposed mechanism of the ion transport is reasonable to explain the experimental characteristics. This result will contribute to understand and utilize biological reactions concerning membrane transports.

\section{References}

1) T. Hanai, Maku to Ion. Kagakudojin: Kyoto, 1978 [in
Japanese].

2) S. G. Schultz, Basic principles of membrane transport. Cambridge University Press: Cambridge, 1980.

3) C. J. Bender and H. T. Tien, Anal. Chim. Acta, 198, 259 (1987).

4) O. H. Le Blanc, Biochim. Biophys. Acta-Biomembranes., 193, 350 (1969).

5) E. A. Liberman and V. P. Topaly, Biochim. Biophys. Acta-Biomembranes., 163, 125 (1968).

6) O. Shirai, S. Kihara, Y. Yoshida, and M. Matsui, J. Electroanal. Chem., 389, 61 (1995).

7) O. Shirai, Y. Yoshida, M. Matsui, K. Maeda, and S. Kihara, Bull. Chem. Soc. Jpn., 69, 3151 (1996).

8) J. Onishi, K. Kano, and O. Shirai, Bunseki Kagaku, 56, 965 (2007) [in Japanese].

9) O. Shirai, Y. Yoshida, S. Kihara, T. Ohnuki, A. Uehara, and H. Yamana, J. Electroanal. Chem., 595, 53 (2006).

10) S. Ozaki, O. Shirai, S. Kihara, and K. Kano, Electrochem. Commun., 9, 2266 (2007).

11） T. Hanai, J. Jpn. Med. Assoc., 70, 1372 (1973).

12) Y. Yoshida, M. Matsui, O. Shirai, K. Maeda, and S. Kihara, Anal. Chim. Acta, 373, 213 (1998).

13) T. Osakai and K. Ebina, J. Phys. Chem. B., 102, 5691 (1998).

14) Y. Marcus, Biophys. Chem., 51, 111 (1994). 